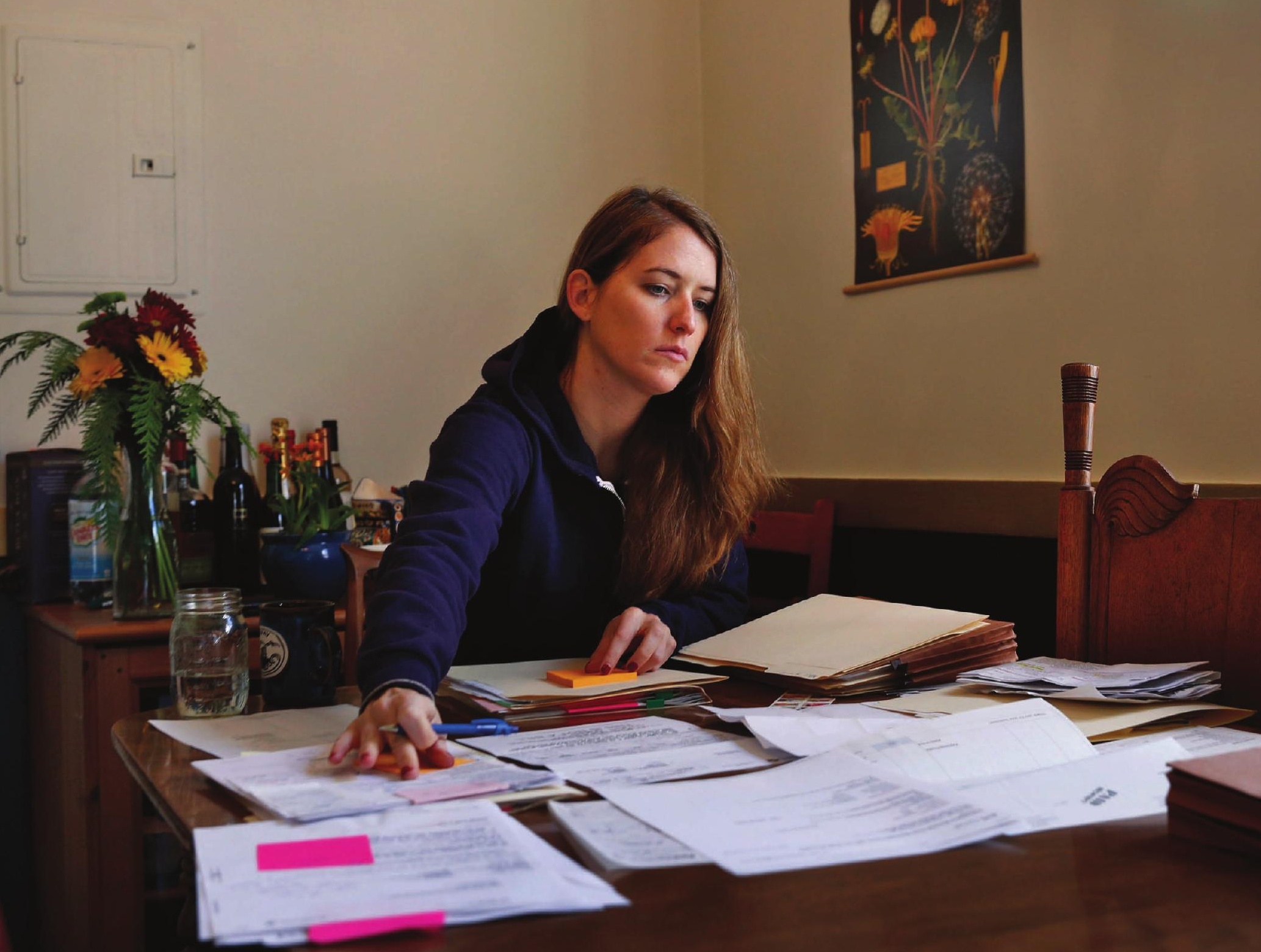

Elizabeth Allen keeps careful records of the many treatments she has undergone to relieve the symptoms of chronic fatigue syndrome.

\title{
The invisible disability
}

\section{Research into chronic fatigue syndrome has a rocky past. Now scientists may finally be finding their footing.}

BY AMY MAXMEN
$\mathrm{N}$ ame a remedy, and chances are that Elizabeth Allen has tried it: acupuncture, antibiotics, antivirals, Chinese herbs, cognitive behavioural therapy and at least two dozen more. She hates dabbling in so many treatments, but does so because she longs for the healthy days of her past. The 34-year-old lawyer was a competitive swimmer at an Ivy-league university when she first fell ill with chronic fatigue syndrome, 14 years ago. Her meticulous records demonstrate that this elusive malady is much worse than ordinary exhaustion. "Last year, I went to 117 doctor appointments and I paid $\$ 18,000$ in out-of-pocket expenses," she says.

Dumbfounded that physicians knew so little about chronic fatigue syndrome - also known as myalgic encephalomyelitis or ME/CFS Allen resolved several years ago to take part in any study that would have her. In 2017, she got her chance: she entered a study assessing how women with ME/CFS respond to synthetic hormones.

After decades of pleading, people with the condition have finally caught the attention of mainstream science - and dozens of 
exploratory studies are now under way. Scientists entering the field are using the powerful tools of modern molecular biology to search for any genes, proteins, cells and possible infectious agents involved. They hope the work will yield a laboratory test to diagnose ME/CFS - which might have several different causes and manifestations and they want to identify molecular pathways to target with drugs.

The US National Institutes of Health (NIH) in Bethesda, Maryland, bolstered the field last year by more than doubling spending for research into the condition, from around US\$6 million in 2016 to $\$ 15$ million in 2017. Included in that amount are funds for four ME/CFS research hubs in the United States that will between them receive $\$ 36$ million over the next five years.

The stakes are high because the field's scientific reputation has been marred by controversial research. A 2009 report $^{1}$ that a retrovirus called XMRV could underlie the disease was greeted with fanfare only to be retracted two years later. And in 2011 and 2013, a British team reported that exercise and cognitive behavioural therapy relieved the symptoms of ME/CFS for many people in a large clinical study called the PACE trial ${ }^{2,3}$. US and UK health authorities had made recommendations based on the findings, but, starting around 2015, scientists and patient advocates began publicly criticizing the trial for what they saw as flaws in its design. The organizers of the trial deny that there were serious problems with it, but health officials in both countries have nevertheless been revising their guidelines.

Patients, meanwhile, are adrift in a vacuum of knowledge about the condition, says Jose Montoya, an infectious-disease specialist at Stanford Medical School in California and one of Allen's physicians. "ME/CFS has suffered from scientists applying the usual approaches," he says. He hopes that sophisticated analyses of genomics, proteomics, metabolomics and more will help to change that. "It wasn't until the microscope became available that an Italian microbiologist could link cholera to the bacteria that caused it," he says. "In the same sense, we have not had the equivalent to the microscope until now."

\section{EARLY DAYS}

In 1984 and 1985, an epidemic of persistent fatigue broke out in Lake Tahoe, Nevada. The US Centers for Disease Control and Prevention (CDC) tested people for Epstein-Barr virus, one cause of the fatigue-inducing illness called mononucleosis or glandular fever, but the results were inconclusive and the investigation was dropped. Around 1987, researchers coined the name chronic fatigue syndrome. But the media snidely called it 'yuppie flu'. Doctors often told people their symptoms were caused by neuroses and depression.

But a small fraction of clinicians listened closely to patients - who insisted that their debilitating exhaustion was not just in their minds. And whereas a little exercise might temporarily uplift someone with depression, individuals with ME/CFS would be bedridden for days after exertion. Some people also struggle with chronic impairment, some with intestinal disorders, and others completely lose the ability to walk. Anthony Komaroff, a physician-scientist at Harvard Medical School in Boston, Massachusetts, began conducting studies on the disease in the mid-1980s despite being discouraged by his colleagues. "I was emboldened by the fact that when I asked my colleagues why they were sceptical, they could not articulate a reason," he says.

In the 1990s, Leonard Jason, a psychology researcher at DePaul University in Chicago, Illinois, started questioning basic epidemiological information on ME/CFS. For one thing, the CDC described the syndrome as rare and predominantly affecting white women. But Jason reasoned that clinicians could be missing many cases. Those who were diagnosed were the ones most likely to return for a second, third or fourth medical opinion. And people who felt stigmatized, were confined to bed, were poor or had little social support might not go to such lengths to get a diagnosis.

So, Jason's team called almost 30,000 random Chicago phone numbers to ask whether someone in the household had symptoms of the disorder. If they did, the team brought them into clinics for evaluation. As a result of the findings from this ${ }^{4}$ and other studies, the CDC removed the word 'rare' from its description of the syndrome. In 2015, a report ${ }^{5}$ from the US Institute of Medicine (IOM) estimated that 836,000 to 2.5 million Americans have the disorder. Another study ${ }^{6}$ estimated that more than 125,000 people in the United Kingdom are living with ME/CFS. And a report ${ }^{7}$ from Nigeria suggests that the prevalence of the disease might be even higher there, perhaps exacerbated by other infectious diseases and poor nutrition. But these tallies are fraught, owing to the different ways in which doctors diagnose the condition.

In many ways, people with ME/CFS remain invisible. Most have been dismissed by at least one physician. And society often ignores them, too. In the United States, financial pressures are common because health insurers might consider experimental treatments unnecessary, and employers might not feel that disability payments are justified. Even in countries where health care is a right, the situation has been dire. Many patient advocates say that UK government agencies have essentially treated ME/CFS as if it were a strictly psychological condition, a conclusion that they argue was bolstered by the PACE trial's findings that exercise and cognitive behavioural therapy relieve symptoms. The National Health Service (NHS) recommended these interventions, even after many patients complained that exercise dramatically worsens their condition.

Epidemiologists have suggested ${ }^{8}$ that the anguish of contending with the disorder and society's general dismissal of it contribute to an up to sevenfold increase in the rate of suicide for people with ME/CFS.

Montoya will never forget one such tragedy. A decade ago, he opened an ME/CFS clinic for half a day each week at Stanford. One afternoon, he received a call from a crying woman whose 45 -year-old daughter had returned home to California after falling ill with ME/ CFS. The daughter had read about Montoya's clinic online and wanted an appointment, but Montoya was booked for a couple of years. In her suicide note, he says, the daughter asked that her brain be donated to him for research. "I feel so guilty, since those were the years with hundreds of patients on the waiting list," he says.

\section{IMMUNE SYSTEM}

Today, Montoya's clinic is open five days a week. And in his research, he's exploring several avenues. The hormone study in which Allen is participating is looking for changes in how the endocrine system is regulated among people with $\mathrm{ME} / \mathrm{CFS}$, a factor that might explain why the disorder is more common in women than in men. But Montoya's leading hypothesis is that ME/CFS begins with an infection that throws the immune system out of whack.

Infections generally lead to inflammation when protein receptors on T cells, a kind of immune cell, recognize corresponding proteins carried by bacteria, parasites or viruses. The T cells multiply and catalyse an inflammatory attack that includes the replication of antibody-producing immune cells, called B cells. In the past few years, researchers have revealed hints of an unusual immune response in ME/CFS. Most recently, last June, Montoya and his colleagues revealed $^{9}$ abnormalities in the levels of 17 immune-system proteins called cytokines in people with severe cases of the syndrome. What 
disrupts the inflammatory response, however, remains unknown. One possibility is that, as in some autoimmune disorders, T cells mistakenly become alarmed by one of the body's own proteins, rather than by an invader, and B cells secrete self-reactive antibodies.

An accidental finding has lent support to this idea. In 2008, Øystein Fluge, an oncologist at Haukeland University Hospital in Bergen, Norway, treated a lymphoma patient with rituximab, an antibody therapy that kills B cells. The patient told him that the drug resolved their ME/CFS. Fluge and his colleagues then conducted a placebocontrolled trial with 30 people who had the condition (and not cancer), and found that rituximab improved their symptoms ${ }^{10}$. As word spread, Fluge was flooded with hundreds of e-mails from people asking to take part in his trials, and doctors around the world fielded desperate requests for the experimental therapy.

Yet any hopes that Fluge dared to have were dashed last October, as he assessed data from an as-yet unpublished 151-person clinical trial and found that rituximab proved no better than the placebo. Fluge says the finer details of the trial might yet reveal whether a small subset of participants benefited. Like many others, he suspects that ME/ CFS might turn out to be several diseases, with different causes and underlying mechanisms. Therefore, what helps some people might not help others. This effect might not be discernible until researchers can tease out how patients differ from one another. Still, the trial's overall failure suggests that autoimmunity is not the main cause of ME/ CFS, says Derya Unutmaz, an immunologist at the Jackson Laboratory for Genomic Medicine in Farmington, Connecticut. Rather, he speculates that inflammation seen in ME/CFS might result from a problem on the regulatory side of a person's immune system, which normally reins in the T-cell response to innocuous viruses, mould particles or other non-threatening stimuli. "Rituximab's failure is very disappointing for patients, but the fact that such a trial was done is a very important thing in the field," Unutmaz adds. "By ruling this out, we can focus on other directions." This is the kind of scientific response that patient advocates have been fighting for since the 1990s.

\section{METABOLIC SYSTEM AND MICROBIOME}

Newsletters dating back decades document how activists have struggled to be recognized by scientists. In one column from 1998, the co-founder of an ME/CFS organization reports on a conference on the ailment in Boston. She notes that someone from ACT UP, a group known for driving research on HIV, was in attendance, "and may show us how to get more attention for the disease".

Through the 2000s, advocates accused the NIH of favouring grant proposals focused on psychiatric and behavioural studies, as opposed to those exploring physiological pathways. A sea change occurred in 2015, however, with the IOM's review ${ }^{5}$ of more than 9,000 scientific articles. "The primary message of this report," concluded the IOM, "is that ME/CFS is a serious, chronic, complex and systemic disease." Soon afterwards, NIH director Francis Collins said that the agency would support basic science to work out the mechanisms of the syndrome.

In September last year, the NIH announced the winners of new grants in support of research hubs looking into ME/CFS. Some of the projects sound as if they duplicate each other, but that's by design. Walter Koroshetz, head of the NIH's National Institute of Neurological Disorders and Stroke in Bethesda and chair of the Trans-NIH ME/CFS Working Group, explains that the NIH sees strength in replication. "There has not been a coordinated effort to follow up on publications and to figure out which findings are most important, which can be reproduced and which fall away when you look at a different patient population," he says. For this reason, one of the NIH grants goes towards a centre at Research Triangle
Institute in North Carolina that will merge ME/CFS data.

A \$10-million, 5-year grant is also going to Unutmaz, who is studying the interplay between the immunological, metabolic and nervous systems of people with ME/CFS. As part of this, he will collaborate with microbiologists to assess the bacteria living in patients' bodies, and to see how shifts in those populations alter metabolites, such as glucose, that may in turn affect inflammation. Unutmaz admits that his studies are at an early stage, and says the point is to generate data to form sharper hypotheses. "We don't know what we don't know in this disease," he says. Researchers at Columbia University in New York City and Cornell University in Ithaca, New York, have won NIH grants to explore some of the same themes, and to delve into inflammation in the brain.

Some CFS researchers argue that the NIH's contribution remains too lean. "A real problem is that funders want to see papers coming out in a short time period, but this is a complex disease that requires long-term studies that are expensive to conduct," says Eleanor Riley, an immunologist at the University of Edinburgh, UK. Beginning in 2013, Riley helped to launch and maintain an NIH-supported biobank of ME/CFS samples at the London School of Hygiene and Tropical Medicine. But the bank has been limited by funding constraints.

Ronald Davis, a biochemist who directs Stanford's Genome Technology Center, says that he too struggles to fund his lab's work on ME/CFS. He points out that although HIV affects roughly the same number of people in the United States - about 1.2 million - it received 200 times as much funding from the NIH as ME/CFS did in 2017.

In December, the Open Medicine Foundation in Agoura Hills, California, a research charity that Davis advises, announced its support for an ME/CFS collaborative centre led by him. In one project, the team intends to finish analysing the complete genomes of 20 people severely ill with ME/CFS, along with the genomes of their family members, to look for a genetic predisposition to the disease. Another project involves the development of what could be the first diagnostic test for ME/CFS.

That test uses a small device containing 2,500 electrodes that measure electrical resistance in immune cells and plasma from blood. When Davis exposed blood samples from people with ME/CFS to a stressor - a splash of salt - the chip revealed that the blood did not recover as well as samples from healthy adults. Davis is holding out on pronouncements, however, until he has conducted a study large enough to show clear and statistically significant effects - including a difference between people with ME/ CFS and those with other conditions. "With XMRV, the problem was that people jumped to conclusions," Davis says. "I've learned that if it's exciting, it's probably wrong."

Davis knows the pain of disappointment personally. He started studying ME/CFS in 2008, when his son, Whitney Dafoe, became incapacitated by the disease. Dafoe volunteered to be studied at his father's centre. A member of the team, Laurel Crosby, recalls exchanging e-mails with Dafoe, discussing the research. But as Dafoe's condition got worse, he stopped replying in sentences, and began answering text messages with just a ' $\mathrm{Y}$ ' or an ' $\mathrm{N}$ '. Then those, too, stopped coming. Dafoe, now 34 years old, can no longer speak. He communicates with his parents through small motions, such as ripping holes in the shape of hearts in paper towels.

A poster of Dafoe hangs in his father's office. In it, he is standing on a beach in northern California with his arms raised towards the sky. Davis took the photo on one of the last days his son could walk. "Now he cannot talk, he can't listen to music, he can't write, he lays in bed all day, and there are thousands of patients like this, patients who are embarrassed to be told that nothing is wrong with them," Davis 


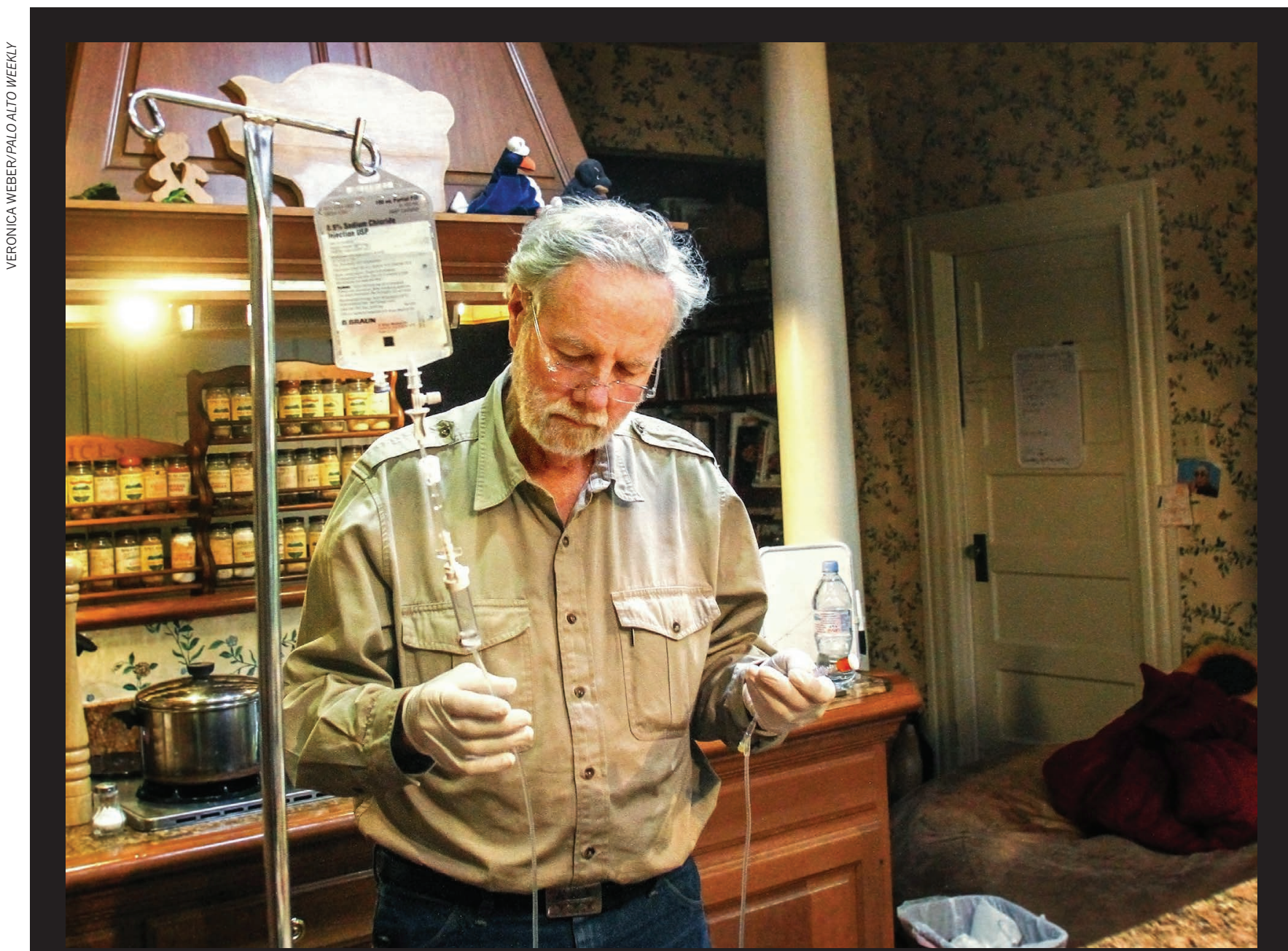

Researcher Ronald Davis prepares a treatment for his son, Whitney Dafoe, who has chronic fatigue syndrome and can no longer walk or speak.

says. So he is furiously testing the electrical device, as well as screening blood samples for proteins and genetic signatures that might reveal a biomarker for the disease. Not having clear criteria for a diagnosis has made clinical trials particularly challenging.

In 2015, David Tuller, a journalist turned ME/CFS advocate, published a critique of the PACE studies ${ }^{11}$. Weeks later, six researchers signed an open letter to the editor of The Lancet, which published the initial PACE results, requesting a reanalysis of the data (see go.nature. com/2z9inlg). Last March, scientists and advocates did the same in a letter to Psychological Medicine - the journal that published the 2013 $\mathrm{PACE}$ results - requesting a retraction (see go.nature.com/2brb5yx). A leading criticism was that the investigators had changed how they measured recovery during the course of the trial, making that outcome simpler to achieve. The PACE investigators have denied this charge and others on their website, writing that changes were made before they analysed the data, and wouldn't have affected the results.

Patients and advocates disagree, and although the paper has not been retracted, the CDC subsequently abandoned the trial's recommendations. In September last year, the NHS announced that it would also revise its recommendations. In a corresponding report ${ }^{12}$, a panel concluded that recent biological models based on measurable physiological abnormalities require greater consideration.

Despite the setbacks and the long delays, many argue that science is operating as it should - being self-critical and open to revision. In five years' time, researchers should be able to pinpoint specific aberrations in the immune, metabolic, endocrine or nervous systems of people with ME/CFS, and perhaps find genetic predispositions to the condition. These indicators might yield diagnostic tests - and, further down the road, treatments.

Allen did not enrol in Montoya's study with the expectation of a cure around the corner. She says she'll be happy if - at the very least - a younger generation can avoid the complete bewilderment she felt when her body suddenly failed her. "I know how long science takes," says Allen. "I am going to try and do whatever I can do to make it move forward as fast as possible." -

\section{Amy Maxmen writes for Nature from San Francisco, California.}

1. Lombardi, V. C. et al. Science 326, 585-589 (2009).

2. White, P. D. et al. Lancet 377, 823-836 (2011).

3. White, P. D., Goldsmith, K., Johnson, A. L., Chalder, T. \& Sharpe, M. Psychol. Med. 43, 2227-2235 (2013).

4. Jason, L. A. et al. Arch. Intern. Med. 159, 2129-2137 (1999).

5. Institute of Medicine. Beyond Myalgic Encephalomyelitis/Chronic Fatigue Syndrome: Redefining an IIIness (National Academies Press, 2015); available at http://go.nature.com/2kydjdi

6. Nacul, L. C. et al. BMC Med. 9, 91 (2011).

7. Njoku, M. G. C., Jason, L. A. \& Torres-Harding, S. R. J. Health Psychol. 12, 461-474 (2007).

8. Kaupur, N. \& Webb, R. Lancet 387, 1596-1597 (2016)

9. Montoya, J. G. et al. Proc. Natl Acad. Sci. USA 114, E7150-E7158 (2017). 10.Fluge, Ø. et al. PLoS ONE 6, e26358 (2011).

11.Tuller, D. 'Trial by error: The Troubling Case of the PACE Chronic Fatigue Syndrome Study' Virology Blog (2015); available at http://go.nature. com/2j5fip7

12. National Institute for Health and Care Excellence. Surveillance report 2017 - Chronic fatigue syndrome/myalgic encephalomyelitis (or encephalopathy): diagnosis and management (2007) NICE guideline CG53 (NICE, 2017); available at http://go.nature.com/2d4ckro 